\title{
Aggregate Fluctuations and International Migration
}

\author{
Michel Beine $^{\mathrm{a}}$, Pauline Bourgeon ${ }^{\mathrm{b}}$, Jean-Charles Bricongne ${ }^{\mathrm{c}, *}$ \\ ${ }^{a}$ CREA, University of Luxembourg, CES-Ifo and Banque de France \\ address: 162a av. de la Faiencerie, L-1511 Luxembourg \\ ${ }^{b}$ Banque de France and Paris School of Economics (University Paris 1) \\ ${ }^{c}$ Banque de France, Rue Croix des Petits Champs, 75001 Paris, France \\ European Commission, DG for Economic and Financial Affairs, Rue de la Loi 170, B-1049 Brussels, \\ Belgium
}

\begin{abstract}
Traditional theories of integration such as the optimum currency area approach attribute a prominent role to international labour mobility in coping with relative economic fluctuations between countries. However, recent studies on international migration have overlooked the role of short-run factors such as business cycles or changes in employment rates in explaining international migration flows. This paper aims to fill that gap. We first derive a model of optimal migration choice based on an extension of the traditional Random Utility Model. Our model predicts that an improvement in the economic activity in a potential destination country relative to any origin country may trigger some additional migration flows on top of the impact exerted by long-run factors such as the wage differential or the bilateral distance. Compiling a dataset with annual gross migration flows between most developed countries over the 1980-2010 period, we empirically test the magnitude of the effect of these short-run factors on bilateral flows. Our econometric results indicate that aggregate fluctuations and employment rates affect the intensity of bilateral migration flows. We also provide compelling evidence that the Schengen agreement and the introduction of the euro significantly raised the international mobility of workers between the member countries.
\end{abstract}

Keywords: International Migration, Business cycles, OECD countries, Income Maximization, Optimum Currency Area,

${ }^{*}$ Corresponding author: European Commission, DG for Economic and Financial Affairs, Rue de la Loi 170, B-1049 Brussels, Belgium; + 3222958029

Email addresses: michel.beine@uni.lu (Michel Beine), pauline.bourgeon@malix.univ-paris1.fr (Pauline Bourgeon), jean-charles.bricongne@ec.europa.eu (Jean-Charles Bricongne) 


\section{Introduction}

International movements of workers between OECD countries have steadily increased over the last 50 years. According to OECD data, this trend clearly intensified as of the early 1980s. ${ }^{1}$ Historically, migration has always been a labor market alternative strategy for economic agents. In the face of adverse economic developments, households or workers may choose to migrate to a particular external country (from a set of alternative destinations) based on considerations that are essentially related to expectations regarding future income. Such decisions are generally based on their perceptions of current and future economic conditions both within their country of origin and in a number of potential destinations. Although many other factors are relevant for migration decisions, this paper focuses on the role of short-run economic factors in shaping the migration choice, and in particular on the role of business cycle fluctuations and employment prospects.

For many years, economists have considered labour mobility as an important macroeconomic adjustment mechanism. The literature on optimum currency areas pioneered by Robert Mundell in 1961, has underscored the role of labor mobility as an adjustment mechanism within a currency union in the face of asymmetric shocks between the participating countries or regions. The criterion of labour mobility has been used as a key measure in assessing whether or not a particular area represents a so-called optimum currency area. Indeed, during the 90s, numerous studies disqualified Europe as an optimum currency area because of its lack of labour mobility. In contrast, Blanchard and Katz (1992) argued that labour mobility could be seen as a dominant adjustment mechanism in reaction to transitory fluctuations in the United States. In the absence of reliable data on labour movements, the supporting evidence was however obtained via an indirect analysis based on a VAR approach involving price, wage and unemployment dynamics. One of the underlying assumptions used to infer the degree of labour mobility is that mobility of workers will induce wage and employment adjustment. This is a debatable assumption in the light of recent literature on the impact of immigration on wages (see among others Borjas et al. (1996), Card (2001), Docquier et al. (2013) and Ottaviano and Peri (2012)). As an alternative to this indirect approach, this paper proposes a direct analysis of the relationship between labour mobility and business cycle fluctuations, taking advantage of new data on migration flows and building on recent developments in microfounded estimable gravity models. In other words, our aim is to tackle an old problem with a fresh approach.

In particular, we test how international migration flows react to economic fluctuations in a sample of mostly OECD countries. To do so, we build and use data of annual migration flows between about 30 countries over the 1980-2010 period. We also focus on the European Monetary Union (EMU) and on the impact of the Schengen agreement on the degree of labour mobility between EU countries. Such an investigation is useful in assessing whether Europe

\footnotetext{
${ }^{1}$ Cf. OECD, International Migration Outlook 2007.
} 
may be more of an OCA ex-post rather than ex-ante. ${ }^{2}$ If the integration process itself leads to a change in the sensitivity of labour mobility to asymmetric shocks, this in turn lowers the need to rely on alternative adjustment mechanisms within a monetary union.

Our analysis belongs to the extensive literature on the determinants of migration. Up to now, this literature has mostly focused on long-run factors of economic, geographic, cultural and demographic natures. ${ }^{3}$ We build on this extensive literature and extend it by looking at the specific marginal role of short-run factors such as the business cycle and the employment rate. In doing so, we integrate the traditional impact of long-run factors identified in the previous literature in order to isolate the specific role of the short-run variables.

There is, however, a body of recent literature acknowledging the importance of short-run factors. Coulombe (2006) empirically investigates the determinants of internal labor mobility in Canada. He finds an important role for the wage differentials between Canadian provinces but finds no impact from business cycle fluctuations. Simpson and Sparber (2012) disentangle the reaction of immigrant inflows to short-run and long-run factors between U.S. States. Other papers also consider these short-run factors in an international perspective. Mc Kenzie et al. (2014) focus on the impact of economic fluctuations in destinations on the intensity of emigration from the Philippines. Bertoli et al. (2013b) analyze the reaction of German immigration flows to the onset of the economic crisis in Europe. We contribute to this literature by generalizing this type of approach to a large set of origin and destination countries over a period including various episodes of macroeconomic fluctuations. In turn, the use of a large pool of origin and destination countries observed over a relatively long period gives additional flexibility in the empirical identification of the factors. One important element is our use of relative measures of business cycle fluctuations and employment rates allowing to capture different situations in both origin and destination countries.

Our empirical strategy directly results from the derivation of a random utility model commonly used in the literature of determinants of migration (Borjas (1987), Grogger and Hanson (2011), Beine et al. (2011)). The income maximization framework allows the modelling of migrants' choices of destination from a set of alternative destinations. The traditional benchmark model is extended to allow some role for short-run factors. In the model, business cycles and current employment rates exert an ultimate role on migration as they signal the evolution of future employment opportunities for economic agents. The theoretical equilibrium then leads to a pseudo-gravity model of international migration which can be readily estimated (Anderson,

\footnotetext{
${ }^{2}$ Work in this area was primarily conducted in the 90s, but using different criteria. See for instance Frankel and Rose (1998) relating trade integration to the asymmetry in business cycle fluctuations.

${ }^{3}$ Since the early work of Mayda (2010), empirical literature on the determinants of migration has developed rapidly. For instance, among many others, Chiquiar and Hanson (2005) focus on the role of education. Grogger and Hanson (2011) look at the role of wages while Rosenzweig (2006) focuses on skill prices. Other papers such as Beine et al. (2011) or McKenzie and Rapoport (2010) look at the role of networks. Clark et al. (2007) investigate the role of distance in a broad sense. Beine and Parsons (2014) focus on push factors like climatic shocks and natural disasters. Bertoli and Fernandez-Huerta Moraga (2012) investigate the role of bilateral migration policies.
} 
(2011)).

To sum up, our contribution is thus fourfold. First, we look at the importance of cyclical shocks in explaining international migration flows in a cross-country perspective. Second, we derive an empirical specification with theoretical microfoundations. Third, we compile a complete dataset of annual gross bilateral flows covering a large set of countries over 1980-2010 and including macroeconomic indicators both at origin and at destination. Fourth, this overall framework allows us to account for short-run and long-run factors within the same model. Our results suggest that short-run economic developments (business cycles fluctuations and employment prospects) affect the level of bilateral migrant flows on top of the long-run factors such as the wage differential. As a by-product of the empirical analysis, we also provide evidence that the Schengen agreement and the introduction of the euro significantly raised international mobility between countries.

The remainder of the paper is organized as follows. Section 2 presents the theoretical foundations of our empirical model. Section 3 describes in detail the data used, thereby providing a number of stylized facts on migration flows. Section 4 outlines the econometric model(s) and presents the main empirical results and section 5 concludes.

\section{Theoretical background: the income maximization approach}

Our theoretical foundation is derived from the income maximization framework, which is used to identify the main determinants of international migration and to pin down our empirical specification. The income maximization approach was first introduced by Roy (1951) and Borjas (1987) and further developed by Grogger and Hanson (2011) and Beine et al. (2011). It is also directly related to the extensive literature dealing with discrete choice models initiated by the seminal work of McFadden (1984). This approach allows to capture migrants' choices of destination from a set of alternative destinations. The theoretical equilibrium leads to the use of pseudo-gravity models of international migration which can be readily estimated (on this point, see Anderson (2011)). One of the main strengths of the income maximization approach is its ability to generate predictions in line with the recent (macro-economic) literature on international migration. By grounding our empirical specification in a theory with a wellestablished track record, we try to eliminate any ad-hoc specifications and to rationalize the obtained empirical relationships. This model has been successfully applied to analysis of the impact of various determinants of international migration. For instance, it has been used to capture the specific role of wage differentials (Grogger and Hanson (2011)), the significance of social networks (Beine et al. (2011)), the "brain-drain" phenomenon (Gibson and McKenzie, (2011)) and the impact of climatic factors (Beine and Parsons (2014)).

Our model considers homogeneous agents who decide their optimal location. Agents therefore maximize their expected utility across the full set of possible destinations which includes the home country as well as all possible foreign countries globally. In this study, we analyze migrations among developed countries. All included countries are therefore considered as 
potential origin and destination countries. Time is included and the model is estimated over a period ranging from 1980 onwards using annual data. In contrast with the benchmark model of Random Utility Maximisation used by McFadden (1984), we do not assume full employment at origin and destination. In the traditional model, agents do not face any uncertainty about future employment, so that what matters for their optimal decision is only the amplitude of wage differential and the level of migration costs. In a world with unemployment rates closer to $10 \%$ rather than to what can be viewed as the natural unemployment rate, this assumption may well be too strong. We therefore extend the traditional RUM approach and assumed that agents will form expectations of future employment based on information provided by the current state of the economy. This involves the current level of economic activity (here, the business cycle) and the current employment rate.

\subsection{Utility, income, unemployment and expectations}

An individual's utility is log-linear in expected income $\left(E\left(y_{i, t}\right)\right)$ and depends on the characteristics of his country of residence, the characteristics of any particular destination among the set of potential destinations, and the costs of moving between the origin and the selected destination. ${ }^{4}$ The utility of an individual born in country $i$ and staying in country $i$ at time $t$ is given by:

$$
u_{i i, t}=\ln \left(E\left(y_{i, t}\right)\right)+A_{i, t}+\varepsilon_{i, t}
$$

where $A_{i, t}$ denotes country $i$ 's characteristics (amenities, public expenditures, social benefits and other push or pull factors) and $\varepsilon_{i, t}$ is an iid extreme-value distributed random term. The utility related to migration from country $i$ to country $j$ at time $t$ is given by:

$$
u_{i j, t}=\ln \left(E\left(y_{j, t}\right)\right)+A_{j, t}-C_{i j, t}(.)+\varepsilon_{j, t}
$$

where $C_{i j, t}($.$) denotes the migration costs of moving from i$ to $j$ at time $t$. In this framework, $\varepsilon_{i, t}$ satisfies the hypothesis of the independence of irrelevant alternatives (IIA) (see McFadden, 1984)..$^{5}$

Agents form expectations regarding the future incomes prevailing in all possible destinations including their country of origin. Expected incomes in country $i$ and country $j$ are given by the expected income conditional upon being employed (the average wage level) times the expected probability of being employed in that country. We do not consider here the role of

\footnotetext{
${ }^{4}$ The assumption of a log-linear utility function is discussed in Anderson (2011). Note that in contrast with utility linear in income, the log-linear utility implies constant relative risk aversion (with a degree of relative risk aversion equal to 1). Endogeneizing the wages, Anderson (2011) derives a pseudo-gravity model including inward and outward multilateral resistance for a degree of relative risk aversion equal to 2 .

${ }^{5}$ This hypothesis implies a constant rate of substitution between alternative destinations. In the econometric framework which is derived from this model, deviations from the IIA hypothesis might lead to inconsistent estimators. Therefore, we check after estimation that our estimates are robust to the successive drop of the various destination countries included in the sample.
} 
unemployment benefits at origin as well as at destination and suppose these are equal to zero for the sake of simplicity. For country $i$, expected income is given by:

$$
E\left(y_{i, t}\right)=E\left(y_{i, t} \mid e_{i, t}=1\right) \cdot E\left(e_{i, t}\right)=w_{i, t} \cdot E\left(e_{i, t}\right) .
$$

where $e_{i, t}=1$ if the individual is employed in country $i$ at time $t, 0$ otherwise. $E\left(e_{i, t}\right)$ stands for the expected employment status. Expected income under employment $E\left(y_{i, t} \mid e_{i, t}=1\right)$ is given by the average level $w_{i, t}$. For country $j$, we have:

$$
E\left(y_{j, t}\right)=E\left(y_{j, t} \mid e_{j, t}=1\right) \cdot E\left(e_{j, t}\right)=w_{j, t} \cdot E\left(e_{j, t}\right) .
$$

It is important to make a distinction in the timing of adjustment. In the short run, assuming sticky wages, business cycle fluctuations tend to affect only employment probabilities $e_{i, t}$ and $e_{j, t}$. This hypothesis is consistent with the evidence of sticky real wages in most developed countries, especially given the annual frequency of the data we consider in the empirical part. In the long run, it is of course possible that wages will adjust. Here we disregard the long-run adjustments and focus on the short-run dynamics. ${ }^{6}$

In turn, agents form expectations regarding the probability of being employed in the future. Given that there is uncertainty about the future stance of the economy, the expected probability of employment is supposed to be given by a mixture of the current level of employment in the economy and its current cyclical state. Migrants use both types of information since they encompass different types of information, both in terms of economic mechanisms and in terms of forecast horizon of the employment rate in the country.

The current employment rate is supposed to exert some signal to the migrants about the future rate of employment in the economy through extrapolative expectations. Migrants can directly observe the current employment rate which provides a good prediction of the next period employment rate for a given level of business cycle. The current level of employment rate integrates to a certain extent the impact of past business cycles and some structural effect of the labour market. The current business cycle provides some information which is more forward looking in terms of future employment rates. The rationale behind such a signalling process refers to the feedback mechanisms from output changes to unemployment as captured for instance by Okun's law. This law relates the business cycle and future labour market tightness at the aggregate level. Empirical literature has shown the relevance of this law in many developed countries and has also documented that there are lags in the transmission of the cycle to the labour market. ${ }^{7}$ While positive, the correlation between the current employment

\footnotetext{
${ }^{6}$ This adjustment can take different forms. One possibility is that there is a compensating mechanism triggered by migration, with wages rising with the decrease in employment in a given location. A special case is the Harris-Todaro (1970) one in which compensation is total, i.e. expected incomes $E\left(y_{j, t}\right)$ are equalized across locations. Pissarides and McMaster (1990) find that in the long run, relative wages in British regions compensate for unemployment differences at a rate of 3 for 1.

${ }^{7}$ Early estimates of the transmission lags in the Okun's law amount to about 6 to 8 quarters, i.e. 1.5 to
} 
rate and the business cycle is far from 1, reflecting the complex dynamics between the current employment rate and the business cycle. ${ }^{8}$

Based on these assumptions, the expected probability of employment in country $i$ is given by:

$$
E\left(\operatorname{Prob}\left(e_{i, t}=1\right)\right)=\left(1-u r_{i, t}\right)^{\theta}\left(b c_{i, t}\right)^{\lambda} .
$$

where $u r_{i, t}$ denotes the unemployment rate and $b c_{i, t}$ is a business cycle indicator. This indicator may be expressed on a $0-100 \%$ scale to match the metric in the employment rate. $\theta$ is a parameter capturing the importance of current employment rate for predicting unemployment while $\lambda$ captures the importance of business cycles in the expectation process.

\subsection{Equilibrium migration rate}

At the individual level, the probability to migrate to $j$ depends on the specific distribution for the disturbances $\varepsilon_{i, t}$. McFadden (1974) shows that if $\varepsilon_{i, t}$ follows an i.i.d. type 1 extreme value distribution, the probability of migrating from $i$ to $j$ can be expressed as:

$$
\operatorname{Pr}\left[u_{i j, t}=\max _{k} u_{i k, t}\right]=\frac{\exp \left[U_{i j, t}\right]}{\sum_{k} \exp \left[U_{i k, t}\right]}
$$

At the aggregate level, the corresponding value of this probability takes the form of the share of natives choosing to migrate to $j$, i.e. by $\frac{N_{i j, t}}{N_{i, t}}$ where $N_{i, t}$ is the size of the native population in country $i$ at time $t$ and $N_{i j, t}$ is the number of migrants in the $i$ - $j$ migration corridor at time $t$. Similarly, $N_{i i, t}$ stands for the proportion of workers remaining in their country of origin during period $t$. Substituting (1) and (2) into (6) yields:

$$
\frac{N_{i j, t}}{N_{i, t}}=\frac{\exp \left[\ln \left(w_{j, t}\right)+\theta \ln \left(1-u r_{j, t}\right)+\lambda \ln \left(b c_{j, t}\right)+A_{j, t}-C_{i j, t}\right]}{\sum_{k} \exp \left[\ln \left(w_{k, t}\right)+\theta \ln \left(1-u r_{k, t}\right)+\lambda \ln \left(b c_{k, t}\right)+A_{k, t}-C_{i k, t}\right]}
$$

Likewise we may compute the equilibrium rate of stayers over natives, giving the equilibrium probability for a native to stay in his or her own country rather than emigrating as:

$$
\frac{N_{i i, t}}{N_{i, t}}=\frac{\exp \left[\ln \left(w_{i, t}\right)+\theta \ln \left(1-u r_{i, t}\right)+\lambda \ln \left(b c_{i, t}\right)+A_{i, t}\right]}{\sum_{k} \exp \left[\ln \left(w_{k, t}\right)+\theta \ln \left(1-u r_{k, t}\right)+\lambda \ln \left(b c_{k, t}\right)+A_{k, t}-C_{i k, t}\right]}
$$

2 years. For some recent evidence on Okun's law in OECD countries, see among others Ball et al. (2013) Gordon (2010) and Lee (2000). In general the empirical literature points to the relevance of Okun's law for all developed countries, although with different sensitivities of unemployment rate to output fluctuation. There is also a general controversy on whether there has been a shift in the average key elasticity and on whether there are asymmetries in the response of unemployment to output shocks.

${ }^{8}$ Depending on the measure of the business cycle, the correlation between the relative employment rate and the relative business cycle is comprised between 0.02 and 0.24 . 
The equilibrium bilateral migration rate between $i$ and $j$ is obtained by taking the ratio $\left(N_{i j, t} / N_{i i, t}\right)$ at equilibrium :

$$
\frac{N_{i j, t}}{N_{i i, t}}=\frac{\exp \left[\ln \left(w_{j, t}\right)+\theta \ln \left(1-u r_{j, t}\right)+\lambda \ln \left(b c_{j, t}\right)+A_{j, t}-C_{i j, t}\right]}{\exp \left[\ln \left(w_{i, t}\right)+\theta \ln \left(1-u r_{i, t}\right)+\lambda \ln \left(b c_{i, t}\right)+A_{i, t}\right]}
$$

Taking logs, we obtain an expression giving the log of the bilateral migration rate between $i$ and $j$ over stayers at time t:

$$
\ln \left(\frac{N_{i j, t}}{N_{i i, t}}\right)=\ln \left(\frac{w_{j, t}}{w_{i, t}}\right)+\theta \ln \left(\frac{1-u r_{j, t}}{1-u r_{i, t}}\right)+\lambda \ln \left(\frac{b c_{j, t}}{b c_{i, t}}\right)+A_{j, t}-A_{i, t}-C_{i j, t}
$$

Expression (10) allows us to identify the main components of the aggregate bilateral migration rate: (i) the wage differential in the form of the wage ratio $\left(\frac{w_{j, t}}{w_{i, t}}\right)$, (ii) differential in employment rates, (iii) differential in business cycles; (iv) differential in pull and push factors at destination $A_{j, t}$, and at origin $A_{i, t}$; (v) finally the bilateral migration costs between $i$ and $j, C_{i j, t}$. Given the absence of unemployment benefits, an increase in current unemployment lowers the probability of employment for the individual and increases the differential with respect to the potential destinations. This favors emigration from country $i$.

Note that by construction, the impact of the relative business cycle on the bilateral migration rate is proportional to its importance for building expectations of future employment rate. This reflects the theoretical channel that is favored in the model. Nevertheless, in the empirical part, the estimated value of $\lambda$ could also be driven by alternative channels.

\subsection{Migration costs}

Putting everything together, our cost function may be expressed as:

$$
C_{i j, t}=c\left(x_{i}, x_{j}, x_{i j}, x_{i t}, x_{j t}, x_{t}, x_{i j t}\right)
$$

The cost function is supposed to be separable (i) into time-invariant origin country factors $\left(x_{i}\right)$ such as being an island, being landlocked, time-invariant destination country factors $\left(x_{j}\right)$ such as being an island, being landlocked (ii) country pair specific time-invariant $\left(x_{i j}\right)$ that include for instance linguistic proximity or bilateral migration policies that are constant over the period under investigation, (iii) time-varying origin country factors $\left(x_{i t}\right)$ that include for instance human capital level of the country, (iv) time-varying destination specific factors $\left(x_{j t}\right)$ such as unilateral immigration policies and finally $(\mathrm{v})$ time-invaraint factors common to both origin and destination countries (vi)time-varying pair-specific factors $x_{i j t}$ such as diasporas at destination or time-varying bilateral policies between the origin and the destination, such as the Schengen agreement in Europe. Given the data dimension, all those cost components, except one can be either directly observed or captured by the relevant combination of fixed effects. 


\section{Data}

\subsection{International migration flows}

Estimating equation (10) requires data on bilateral migration flows in gross terms at a business cycle frequency level. To the best of our knowledge, there is no ready-to-use dataset combining these features. The litterature on determinants of migration has mainly exploited data on stocks of migrants. ${ }^{9}$ As previous authors who have studied migration flows, we built our own dataset merging different sources of information. ${ }^{10}$ Since the required variables were available only for a large part of OECD countries, we obtain a data containing 24 destination and 30 origin countries over the period 1980-2010. ${ }^{11}$ Our data therefore captures an important share of total international migration to and from OECD countries and covers many major episodes of economic fluctuations in the modern era. ${ }^{12}$ We can briefly enumerate some of these episodes: the recession following the second oil shock in the early 80's, the recovery of the late eighties in many OECD countries, the US recession in the early nineties, the European recession of the mid-nineties, the US expansion in the late nineties and last but not least the financial crisis in 2008.

Our first source of information for migration flows is the international migration flows dataset from the UN. ${ }^{13}$ This data covers 20 destination countries of our sample. We complement this sample with the OECD International Migration database. ${ }^{14}$ We decided to complement the UN dataset to include four key countries in our analysis (namely, Greece, Ireland, Portugal

\footnotetext{
${ }^{9}$ For instance, two well-known cross-country data on international migration, namely Docquier and Marfouk (2006) on the one hand and Özden et al. (2011) on the other hand are suited more for capturing the longrun determinants of international migration. Docquier et al. (2009) provide bilateral migration stocks with information about education levels (as well as gender) for two years only, 1990 and 2000. Özden et al. (2011) provide a complete coverage at the global level of bilateral stocks for 5 years $(1960,1970,1980,1990$ and 2000) by gender only.

${ }^{10}$ For instance, Belot and Ederveen (2012) build their own dataset to analyse the role of cultural barriers between 22 OECD countries over the 1990-2003 period. Pedersen et al. (2008) build migration flows for 27 OECD countries and more than 120 origin countries for the 1990-2000 period. They combine information provided by the national statistical offices of the destination countries with OECD data extracted from "Trends in International Migration".

${ }^{11}$ The list of destination countries is: Australia, Austria, Belgium, Canada, the Czech Republic, Denmark, Finland, France, Germany, Greece, Iceland, Ireland, Israel, Italy, the Netherlands, New Zealand, Norway, Portugal, Slovenia, Sweden, Switzerland, the United States, Spain and the UK. We include 6 additional origin countries: Croatia, Hungary, Luxembourg, Romania, the Russian Federation, Slovakia

${ }^{12}$ Comparing our data with the most comprehensive data provided by Docquier et al. (2009), we cover most of the migration process between OECD countries. Our data do not include 6 destination countries (out of 30) covered by Docquier et al. (2009): Japan, Korea, Mexico, Poland, Turkey and South Africa. Still, the 24 common destination countries represent respectively 82 and $84 \%$ of total migration stocks captured in Docquier et al. (2009) respectively for 1990 and 2000; and they represent $96 \%$ of skilled migrants observed in 1990 and 2000.

${ }^{13}$ This dataset is provided by the United Nations Population division. More information may be found on http://www.un.org/esa/population/migration/

${ }^{14}$ Downloadable on http://stats.oecd.org/
} 
and the United Kingdom). Aware that aggregating data from multiple sources raises comparability issues we conduct some robustness checks in section 4.2.1.

These two databases provide, for all destination countries, annual migrant inflows by origin country. They gather immigration statistics obtained from National Authorities. Countries do not necessarily adopt the same collection process and may use different criteria to identify immigrants. In order to obtain a sample as harmonized as possible we keep, when possible, the same criterion for all the destinations. Most countries in our sample use the residence criterion, others use the citizenship criterion and only one country uses the country of birth criterion. Appendix A provides greater details on the characteristics of our immigration data. ${ }^{15}$ The residence criterion allows us to capture better short-term mobility since it covers the last origin of migrants, while citizenship and birth criteria capture respectively long-term immigrants and immigrants from a permanent origin. The residence criterion involves the delivery of a residence permit, the duration of stay considered varies among countries. ${ }^{16}$

The resulting dataset contains 21,576 observations but is quite unbalanced. Overall we have a significant number of missing observations but very few zero values. We count 8,090 missing observations i.e $37.5 \%$ of all observations. In contrast, we have only 67 observations corresponding to zero immigration flows, i.e. less than $0.5 \%$ of the non-missing observations. In terms of econometric implications, the low occurrence of zeros allows us to use the traditional panel data methods as opposed to the alternative techniques such as Poisson Maximum likelihood or hurdle models. ${ }^{17}$

The proportion of missing values is unequally distributed across destination countries, reflecting differences in size and quality of data collection. In short, there is a large proportion of missing values in relatively small destination countries such as Greece, Portugal and Israel. There are nevertheless exceptions to that rule, with large developed countries such as France and the UK displaying a relatively high number of missing observations.

Figure 1 reports the number of zeroes and missing observations for the bilateral flows over the full period 1980-2010 for each destination.

[Figure 1 about here.]

\subsection{Wages, business cycles, employment rates}

Estimating the equilibrium equation (10) requires data on wages, business cycles and unemployment rates for destination countries. Many cross-country analyses of migration flows face

\footnotetext{
${ }^{15}$ For countries for which it was possible, we checked the correlation between immigration flows defined with the three alternative criteria (residence, citizenship, birth). We get quite a positive correlation in the range of 0.8. We also conduct robustness regressions on a restricted sample containing only countries using the residence criterion.

${ }^{16}$ More information is available on http://esa.un.org/unmigration/MigrationFlows.html

${ }^{17}$ On this point, see Santos Silva and Tenreyro (2006). These techniques are specifically designed to deal with the statistical consequences of the presence of a large proportion of zeros for the dependent variable.
} 
issues in finding comparable measures of wages across countries. Grogger and Hanson (2011) definitely provide the best approach with respect to this issue, recovering wages by education level from the observed wage distribution in microeconomic databases specific to each destination country. This is made possible however by the relatively low number of countries (only 13) considered in their analysis. Some studies capture wages by proxies such as GDP per capita, which might imply significant measurement errors in some cases. ${ }^{18}$ Other analyses do not directly observe wage data but capture their role through the use of fixed effects. ${ }^{19}$ In this paper, in contrast to those previous studies, we use explicit measures of wages at destination. For the sake of data harmonization we exploit a unique source for all these macroeconomic variables. The data are from the World Economic Outlook of the IMF, they provide wage, GDP and unemployment rate series for all countries of our sample. For most countries, these series span the whole period studied but in some cases (the Czech Republic, Slovenia, and the UK) series begin later.

We extract cyclical stance from GDP data and use two different measures. The first one relies on the deviation from GDP trend and uses the traditional Hodrick-Prescott filter for that purpose. Given the annual frequency, we extract the trend based on a value of the smoothing parameter $\lambda$ equal to 400. As an alternative, we use a more simple measure based on the annual growth rate of GDP.

\subsection{Bilateral variables}

In addition to these measures, we also capture time-varying dyadic variables $\left(x_{i j t}\right.$ in terms of expression (11)) thought to affect bilateral migration costs. We use three main measures to tackle integration between countries: (i) Schengen agreement between (a subset of) EU countries, (ii) other bilateral agreements favouring the international mobility of workers and (iii) joint membership of the European Monetary Union. These measures are explained below. The exact construction and sources of the bilateral agreements are also described more in details in Appendix A.

The Schengen variable $\left(\right.$ Schengen $\left._{i j, t}\right)$ is a time-moving dyadic variable taking 1 if both countries had implemented the Schengen rule at time $t$, and 0 otherwise. The Schengen agreement was progressively signed and implemented by a subset of EU countries and was designed to favour mobility between EU countries. By harmonizing rules for getting work permits, these agreements increased labour mobility between the signing countries and provide a complementary frawework with respect to mere EU membership. ${ }^{20}$ We take into account the

\footnotetext{
${ }^{18}$ See for instance Beine and Parsons (2014) who capture wage differentials by differences in GDP per capita for all origin and destination countries.

${ }^{19}$ See for instance Beine et al. (2011) and Bertoli and Fernandez-Huerta Moraga (2013a).

${ }^{20}$ Basically, countries that signed the Schengen agreement tend to transfer the rules of entry and the conditions of work to the European Union. These rules are harmonized. For instance, people migrating within the Schengen area are not subject to any control at the border. The signatory states to the agreement have
} 
implementation criterion, i.e. by considering cases in which the country signed and implemented the Schengen rules of people mobility. There is a significant variation of member and non-member EU countries. ${ }^{21}$ There is also a significant variation in terms of timing between member countries of the Schengen area. ${ }^{22}$ Second, we capture the fact that both the origin and the destination countries belong to the European Monetary Union (EMU) that for a subset of EU countries was launched in 1999. The use of a common currency between countries should imply a significant drop in currency conversion costs between the destination and the origin countries for migrants. It also favours direct comparison of economic aggregates between countries, such as wages and prices. EMU implementation also led to facilities and economies in terms of international bank transfers. There is also a drop in uncertainty regarding the converted wage amount at destination due to the full eradication of bilateral exchange rate volatility. It is important if the prospective migrants intend to remit part of their earnings to their relatives staying behind. As for the Schengen agreement, the $E M U_{i j, t}$ variable takes 1 if both countries were EMU members at time $t$, and 0 otherwise. As for the Schengen agreement, there is a balanced mix of EMU and non-EMU members in our sample of countries. There is also a significant variation between member countries in terms of timing of adhesion to the EMU for our sample of origin and destination.

Finally, we capture the existence of bilateral agreements in terms of labour mobility between countries included in the sample beyond the agreements specific to EU countries. These bilateral agreements are supposed to facilitate the migration of economic agents through a set of mechanisms. For example, one mechanism goes through the visa waiving arrangements for the candidates to migration. We build a dyadic dummy variable Bilateral $_{i j, t}$ taking 1 if there is a bilateral agreement at time $t$ favouring the mobility of workers between countries $i$ and $j$, and 0 otherwise. The existence of those bilateral agreements is identified using the agreements collected by the International Organization of Migration (IOM). Details about the sources and the exact nature of those agreements are provided in Appendix A. We find that out of 21576 possible observations, we have 871 observations for which there was a bilateral agreement of that kind between the two countries at that time. This represents about $3 \%$ of the observations.

abolished all internal borders in lieu of a single external border. Here common rules and procedures are applied with regard to visas for short stays, asylum requests and border controls. In contrast, the citizens of countries that are member of the European Union but not of the Schengen area remain subject to the national rules of each destination country regarding the entry and the conditions of stay in the country. This has also some consequences for the conditions under which the migrants can work. For instance, in the period analyzed in our article, in France, citizens from Romania could work, but only in 291 occupations experiencing recruitment difficulties. This example illustrates that the Schengen agreement is important for job-related migration.

${ }^{21}$ Among the EU countries, Ireland and the UK and Croatia are not members.

${ }^{22}$ Basically, implementation for signing members followed three different waves. The first wave took place for most of the European founders around 1995-1997. A second wave concerning mostly Scandinavian countries plus Greece occurred around 2000-2001. Finally joining East European countries implemented the Schengen agreement around 2007. 


\section{Estimation}

We start from equation (10) and estimate a benchmark specification that is consistent with the equilibrium equation. We propose different specifications depending on the specification of the cost component in equation (11).

\subsection{The benchmark specification}

Combining equations (10) and (11), we estimate the following benchmark equation:

$$
\begin{aligned}
\ln \left(N_{i j, t}\right)=\beta_{0}+\beta_{1} \ln \left(w_{j, t}\right)+\beta_{2} \ln & \left(1-u r_{j, t}\right)+\beta_{3}\left(b_{j, t}\right)+\beta_{4} \text { Schengen }_{i j, t} \\
& +\beta_{5} E M U_{i j, t}+\beta_{6} \text { Bilateral }_{i j, t}\left[+\alpha_{i j}\right]\left[+\alpha_{j}\right]+\alpha_{i t}+\epsilon_{i j, t}
\end{aligned}
$$

Schengen $_{i j, t}, E M U_{i j, t}$ and Bilateral $_{i j, t}$ are respectively dummy variables capturing the joint participation at time $t$ to the Schengen agreement, the joint participation at time $t$ to the European Monetary Union and the existence at time $t$ of other bilateral agreements favoring worker's mobility between the two countries as defined in the previous section.

Importantly, this specification includes $\alpha_{i t}$ fixed effects. The purpose of these effects is manyfold. First, in terms of the equilibrium equation (10) one can see that $\alpha_{i t}=\ln \left(N_{i i, t}\right)+$ $\beta_{1} \ln \left(w_{i t}\right)+\beta_{2} \ln \left(b c_{i t}\right)+\beta_{3} \ln \left(1-u r_{i t}\right)+c\left(x_{i t}\right)+c\left(x_{i}\right)+c\left(x_{t}\right)$. This means that the $\alpha_{i t}$ fixed effects account for the role of many factors at origin, such as wages, employment rates and business cycles. The fixed effects also capture the role of migration costs that are specific to the origin, or those which are common to all countries but move over time. Second, the $\alpha_{i t}$ fixed effects account for the role of $\ln \left(N_{i i, t}\right)$, i.e. the total number of native workers of country $i$ staying in their own country at time $t$. This is important because due to lack of data, we do not have a direct observable measure for $\ln \left(N_{i i, t}\right)$. Indeed, in contrast with Beine and Parsons (2014), we do not have full information regarding emigration flows, and rely only on a subset of destinations $j$. Therefore, it is not possible to estimate $N_{i i, t}$ from the population stock $\left(N_{i, t}\right.$ and the full set of emigration flows $\left.\sum_{k} N_{i k, t}\right)$. The inclusion of $\alpha_{i t}$ provides a straightforward solution to the non observability of $\ln \left(N_{i i, t}\right)$ and makes sure our specification is in line with the equilibrium condition. Finally, the inclusion of $\alpha_{i t}$ account for multilateral resistance to migration. Multilateral resistance to migration terms capture the fact that any change in the flow between $i$ and $j$ will affect the other bilateral relationships. Concepts of multilateral resistance have been originally identified in literature analysing bilateral trade flows (Anderson and van Wincoop (2003), Anderson (2011)). It has also recently received some specific attention in the migration literature (see Bertoli and Fernandez-Huertas Moraga (2013a)). ${ }^{23}$ In turn, failure to account for the multilateral resistance to migration might lead to a violation of the underlying

\footnotetext{
${ }^{23}$ Bertoli and Fernandez-Huertas Moraga (2012, 2013a) propose to capture multilateral resistance to migration by using the Pesaran CCE estimator. This requires the use of nests of destination countries. The underlying assumption is that shocks $\epsilon_{i j, t}$ are correlated across countries belonging to the same nests but are independent across countries included in different nests. In the context of our study, the exact composition
} 
independence from irrelevant alternatives (IIA) hypothesis. The IIA hypothesis underlies the discrete choice model à la McFadden (1984) in the income maximization approach that we outlined in section 2. The inclusion of $\alpha_{i t}$ allows to control for (inward) multilateral resistance capturing the incidence of migration costs of the sending countries. This is also the strategy adopted by Ortega and Peri (2013). One way to see if this inclusion does a good job in controlling for multilateral resistance is to evaluate whether the IIA hypothesis seems to hold after estimation of the model. On top of that, we include time-invariant dyadic fixed effects $\alpha_{i j}$. In this set-up, $\alpha_{i j}=c\left(x_{i j}\right)$ in terms of equation (11). In other terms, the dyadic fixed effects capture the part of the migration costs that are pair-specific and time-invariant.

[Table 1 about here.]

The results are reported in Table 1 . Columns (1) and (3) report the results obtained with the HP component as the measure of the business cycle at destination. Columns (2) and (4) report the results obtained with the growth rate as the alternative measure of the business cycle at destination. We estimate each model by OLS and scaled OLS.

Overall, we find evidence in favour of long-run and short-run factors on the bilateral migration flows. First, and importantly, we find a very robust and stable elasticity for the wage differential. An increase of around $10 \%$ in the wage ratio (due to the increase of the wage at destination) leads on average to an increase in the bilateral migration flows of about $7.7 \%$ (see Table 1). This is in line with the findings of the existing literature. Nevertheless, on top of that, we find support for a role of short-run factors, i.e. of business cycles and employment rates. Starting with the specification including the $\alpha_{i j}$ fixed effects, the positive impact of the relative business cycles is observed regardless of the business cyclical stance measure. The same holds for the differential employment rates. These results are consistent with the idea developed in our theoretical framework that the cyclical stance provides an additional signal to the candidates to migration for choosing the optimal destination. According to this interpretation, this signal is in terms of the future probability of employment for those migrants, which ultimately affects the expected wage at destination and in turn the net gain derived from moving to that destination.

The estimation results suggest that short-run factors contribute to the understanding of the variability of bilateral migration flows. Depending on the estimation method and the measure

and the number of the nests would first rely on arbitrary criteria that could be difficult to justify. Furthermore, the use of 31 time periods along with 30 origin countries would lead to a strong inflation of the number of included parameters (871*the number of nests). To illustrate, the inclusion of 6 nests as in Bertoli and Fernandez-Huertas Moraga (2012) would lead to 5226 additional parameters to estimate. Since we rely on the Least Square Dummy Variable approach instead of the within transformation approach -due to the fact that our panel data set is strongly unbalanced (due to zeros, missing observations over time, missing destinations for given origins) (see Baltagi, 1995)-, the implementation of that approach would lead to important computational problems. As a result, while recognizing its value, we disregard the Bertoli and Fernandez-Huertas Moraga (2013a) approach and follow instead the Ortega and Peri (2013) strategy. 
of the business cycle, the decrease in the Root Mean Square Error when adding those factors lies between 2.9 and $3.2 \%$. While this can sound as a modest contribution, one should not forget that the model accounts for many unobserved factors through the set of fixed effects. ${ }^{24}$ While the business cycle seems to enter in migrants' expectations of future employment rates, the relative contribution seems to come mostly from the current employment rates. In terms of economic magnitudes, a rise of $1 \%$ in the ratio of employment rates between the destination and the origin leads to a $5 \%$ increase in the bilateral migration rates. The estimated business cycle elasticities suggest that a $1 \%$ differential in growth rates between the origin and the destination countries leads to a $0.02 \%$ increase in the bilateral migration flow (for columns (2) and (4)). Even though these orders of magnitude seem to be modest, the cumulated effects over the whole business cycle can be substantial, especially for migration corridors that are already important.

To give a more tangible assessment of the impact of employment rates, one may for instance consider the flows from Germany to Italy, which represented between 8,000 and 14,000 migrants over the considered period. Using the fact that a $1 \%$ increase in the ratio of employment rates leads to a $5 \%$ increase in bilateral migrations rates, we find that the rise of the ratio of employment rates, cumulated between 2000 and 2005 ( +6.5 points) contributed to a supplementary cumulated flow of immigrants from Germany of 3,740 persons (620 in average per year). Conversely, when the situation reversed between 2006 and 2008, with a cumulated decrease of the ratio of employment rates of -3 points, this contributed to a cumulated decrease of immigration flows from Germany to Italy of 1,800 persons (600 persons in average per year). Yet, the contribution of the differential in growth rates between the two countries was negligible for this couple of partners. To get more substantial contributions of the differential in growth rates, we can take for example the flows from Romania to Spain, which rose up to around 174,000 in 2007. Between 2001 and 2008, with growth rates that were significantly more important in Romania than in Spain, the differential in growth rates contributed to a cumulated diminution of around 500 immigrants.

An important by-product of our estimation is the impact of the time-varying dyadic factors affecting the migration costs. We find a positive impact on mobility for the Schengen agreement between EU countries, a positive role for currency unification as well as a positive impact for the other bilateral agreements. The positive impact of a common currency has been also found by Ortega and Peri (2013), while the boosting effect of the Schengen agreement was documented to a certain extent by Beine et al. (2011) in a cross-section context. These two results are important in terms of our discussion about the optimal nature of the European

\footnotetext{
${ }^{24}$ One might be concerned about an omitted variable bias caused by the role of international trade. It is important to note that most of bilateral trade is already captured through the origin-time fixe effects. Most determinants of gravity equations arealready present in our specifications (weights, proxied by bilateral fixed effects for initial levels and complemented by GDP growth; origin-destination fixed effects for distances and other bilateral characteristics (common language...); agreements or institutional settings (single currency) that are likely to favour trade...). We therefore do not expect any bias linked to omitted variables due to the role of international trade.
} 
Monetary Union. The traditional Optimum Currency Area literature (Mundell, 1961; De Grauwe, 2009) emphasized the important role of labour mobility in coping with asymmetric business cycle shocks. Our estimation results show that with respect to labour mobility, the Schengen agreement as well as the inception of the euro made Europe closer to an Optimum currency area. This of course does not mean that Europe is or has become an OCA. Nevertheless it shows that integration measures increased the net gains (or decreased the net costs) derived from the introduction of the euro. For example, migration flows from the Netherlands to Belgium, which amounted to around 6,000 in the nineties rose to 12,000 in 2007. The corresponding impact of the euro area, equal to $14 \%$ (Cf. Table 1), would thus represent around 880 migrants. ${ }^{25}$ Also, the results are in line with the new OCA literature that shows that the optimal nature of a monetary union is itself endogenous with the monetary unification process (Frankel and Rose, 1998; Beetsma and Giuliodori, 2010). Frankel and Rose (1998) show that the optimality of a currency union depends on the degree of asymmetric shocks within the union, which itself depends on the monetary unification process. The same holds for the intensity of trade flows. Related to those findings, we show that currency unification decreases the costs of moving between euro area countries, and therefore increases the scope of labour mobility as an alternative adjustment mechanism to the flexibility in exchange rates.

The estimates relative to the impact of bilateral agreements in Table 1 are all found positive, which is in line with the expected impact of bilateral agreements on the migration costs. We find that the existence of bilateral agreements favouring worker mobility between two countries raises the bilateral migration flow by 9 to $10 \%$.

As stressed before, it is important to check whether the validity of the IIA assumption holds after estimation. An indirect way of evaluating this is to look at the stability of estimated coefficients when some destinations are dropped from the estimation sample. This method was used, for example, by Head et al. (1995) for an analysis of location choices in the US by Japanese manufacturing firms during the 1980's. We implement this method by dropping one destination at a time and by plotting the estimated key coefficients. Before examining the patterns of coefficients, two comments are in order. First, we rely on visual examination only rather than on a formal test because our sample is strongly unbalanced. It is unbalanced in several ways. For some country pairs, there may be missing years. For some origins, there might be missing destinations for the whole time period, and for some destinations, there might also be missing origins. Therefore, the removal of different destinations might lead to quite different subsamples. For instance, since the US is the most important destination, removing the US reduces the sample by a maximum number of observations $(30 * 31=930$ data points). In contrast, removing Romania has little impact on the sample as the Romanian destination is widely unavailable for most origins. Tests of equality of estimates with different subsamples

\footnotetext{
${ }^{25}$ Since the coefficient of the euro area variable is related to a dummy, the corresponding elasticity cannot be used directly and is equal to $(\exp (0.14)-1)=0.150$. To take another case, flows from Germany to Italy, between 8,000 and 10,000 in the nineties, rose up to 14,000 in 2004 , with a contribution of the euro area that would thus represent around 700 migrants.
} 
are therefore difficult to implement. Second, the fact that removing different destinations leads to different subsamples means that our evaluation of the IIA assumption is done assuming that there is no selection issue here.

Figure 3 reported in Appendix $\mathrm{C}$ plots the evolution of the estimated key coefficients of equa-

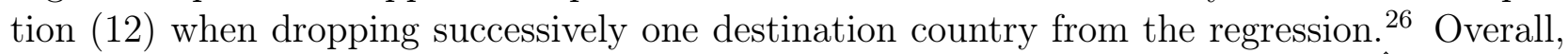
with few exceptions in terms of destinations (Spain) and in terms of coefficients $\left(\hat{\beta}_{2}\right)$ of equation (12), the rolling estimates display quite stable estimated coefficients. ${ }^{27}$ Comparing the key estimated coefficients of Table 1 with the range displayed in those figures, we find that in general the estimated impact is robust to the exclusion of alternative destinations. The estimate of the wage elasticity (0.87) lies more or less in the middle of the range in terms of the coefficients displayed in Figure 3. The same basically holds for the other coefficients of interest, particularly those related to the employment rate, the business cycle and the Schengen agreement.

\subsection{Robustness checks}

\subsubsection{Data homogeneity issues}

In our baseline regression, we use a mix of OECD and UN data, with different criteria (residence, citizenship, birth). In order to validate this choice, we perform two main kinds of robustness checks: First, we exclude observations from data collected by the OECD and focus on UN data only (which implies that a set of destinations are left out of the analysis). This corresponds to columns (1), (2), (5) and (6) of table 2. Second, focusing on the UN data only, we further restrict our attention to one single criterion, namely the residence one, which means losing around $40 \%$ of UN observations. This choice enables, among other things, to include return migrants, i.e. natives coming back to their home countries. This corresponds to remaining columns of table 2: 3rd (scaled OLS, HP filter), 4th (scaled OLS, annual growth rates), 7th (OLS, HP filter) and 8th (OLS, annual growth rates).In all cases, we consider dyadic and origin-time fixed effects.

[Table 2 about here.]

On the whole, if we compare the coefficients $\left(+/-1.96^{*}\right.$ standard errors) of columns (1), (3), (5) and (7) between them and with columns (1) and (3) of Table 1, results are quite robust, even if coefficients of wages and business cycles are somewhat magnified. Conducting the same

\footnotetext{
${ }^{26}$ The measure of the cycle differential is given by the differential in growth rate.

${ }^{27}$ More precisely, the removal of Spain from the sample tends to decrease the magnitude of the impact of the employment differential (but not its statistical significance). This can be rationalized by the fact that Spain is precisely a country having attracted a lot of migrants due to the economic boom and an improving labour market, especially in the 90's and the years prior to the financial crisis. This is well documented in Bertoli and Fernandez-Huerta Moraga (2013a).
} 
comparison involving columns (2), (4), (6) and (8), we see that coefficients are even closer to the ones of columns (2) and (4) of Table 1. The only cases of significant differences are for the Schengen coefficients with a smaller magnitude, which may be explained by the fact that we exclude several Schengen members (Austria, Belgium, France, Greece, the Netherlands, Portugal, Slovenia and Switzerland, for different periods) by sticking to the residence criterion of UN data.

As a complementary robustness check with data, we have performed regressions putting aside the observations for 2009 and 2010, since these recent years may be incomplete, due to the time needed for data collection and processing. The results obtained, which are available upon request, are once again robust.

\subsubsection{Illegal migration and cross-border workers}

By definition, illegal migrations are not included in our data. In our study, this problem is probably mitigated by the fact that we focus on migration between mostly developed countries where illegal migrations are limited (especially compared to cases such as migrants from Mexico to the United States) and that a sizeable part of our sample is between members of the Schengen area, where migration is free.

Yet, since this may be a concern in some cases (current members of the Schengen area have not been concerned by free circulation over the whole period), we have decided to perform a robustness check, in which we exclude observations for which we can expect illegal migrations to be a significant share of the bilateral flows. Since there is no single source about illegal migrations, we have relied on two kinds of sources: country specific reports (US, Norway, Sweden) and area-specific reports (such as the Clandestino report for a subset of EU countries). ${ }^{28}$ To perform as convincing robustness checks as possible, and given the uncertainties linked to the measures of illegal migrations, we have chosen to be conservative, namely in case of doubt about the importance of illegal migrations for a given source and destination country, we have excluded the related flows.

Results, as shown in column (1) and (2) of Table 3 with HP filter and annual growth rates are robust compared to column (3) and (4) respectively of Table 1. For the sake of simplicity, only OLS regressions have been reported in Table 3.

Another issue which is disregarded in the benchmark regressions is the treatment of crossborder workers. Cross-border migration might indeed involve a different process, compared to the usual economic migration. Following the same strategy used above, we reestimate the model excluding the observations for which cross-border workers represent a significant share. This identification of this significance relies on reports, mainly one for the EU-27 and another one on cross border workers between the US and Canada. Once again, results, as shown in column (3) and (4) of Table 3 with HP filter are robust compared to column (3) and (4) of

\footnotetext{
${ }^{28}$ More details about the sources are given in Appendix A
} 
Table 1.

Taking into account these two issues (illegal migrations and cross-border workers) simultaneously, we perform a third set of robustness checks in which we exclude all the origin-destination observations for which at least one of these mobility flows represents a significant part of the recorded flows. The results of this exercise are reported in Table 3 (columns (5) and (6)), which are quite similar to the results of the benchmark regressions in Table 1.

[Table 3 about here.]

\subsection{Caveats: endogeneity and network effect}

\subsubsection{Endogeneity}

One traditional concern in terms of estimation of models such as model (12) is the occurrence of endogeneity. In particular, given the focus of the paper, the potential endogeneity of the aggregate fluctuations should be assessed with great care. For the sake of understanding, it is nevertheless important to identify the sources of endogeneity in this context. Basically, two traditional sources can be considered : (i) reverse causality from international migration to aggregate fluctuations and employment rates and (ii) endogeneity due to omission of factors (due to inobservability for instance) that could be correlated with aggregate fluctuations. One important factor of this kind involves unilateral immigration policies.

\subsubsection{Reverse Causality}

One particular concern is whether international migration can affect the economic conditions, i.e. whether there is a reverse causal relationship from international migration to economic fluctuations and employment rates. One important reason for which this concern is mitigated here is that we rely on bilateral migration flows. Migration flows at the bilateral level remain quite modest with respect to the size of the labour market and the goods market, either at origin or at destination. To illustrate, in our sample, only 6 bilateral flows out of 690 are over the 50,000 threshold. Out of those 6 flows, 3 flows concern Germany as the destination country, with obviously the case of Russian and Romanian migrants in 1990s as outliers. Only 32 country pairs involve flows that are over 20,000 migrants. Those figures suggest than even if economic migration can affect economic outcomes in general, the bilateral nature of our analysis makes this concern much less serious than in unilateral analysis of migration. Even in the unilateral case, the literature is in general very mixed about the potential effect of immigration. To illustrate, the huge literature about the impact of immigration on domestic wages (Borjas, 2006, Card, 2005, Ottaviano and Peri, 2012) is divided about the exact nature of that effect. When conclusions in favour of some effects are drawn, the expected magnitude on domestic wages remains quite modest in economic terms. 


\subsubsection{Omission of unilateral immigration policies}

In the estimation of model (12), immigration policies are explicitly accounted by the Schengen agreement among EU countries as well as by the additional bilateral agreements captured by the IOM database. These variables refer to bilateral policies, i.e. policies that are specific to a particular migration corridor. They include preferential treatments often granted by the host country. Due to absence of data, we do not capture explicitly the other dimension of immigration policies, i.e. the unilateral dimension. These include immigration policies that are conducted towards all the partner countries. Model (12) includes $\alpha_{i t}$ and $\alpha_{i j}$ fixed effects but these do not capture the role of immigration policies conducted by the destination country. One legitimate concern is that the omitted variable can lead to biased estimates. The discussion is mainly about the expected magnitude of that possible bias.

The bias related to the omission of immigration policies materializes if these immigration policies are contemporaneously correlated with our business cycle measures. While one can expect a positive correlation of liberal immigration policies and the business cycle over time, the timing of that correlation is more debatable. A contemporaneous correlation which is needed to generate such a bias requires that the immigration policy and its implementation reacts within a year to adverse or positive economic developments at the country level. While it might be the case for some particular episodes, on average, the design and the implementation of such immigration policies takes time. In other terms, an underlying assumption in our estimates is that the contemporaneous correlation between unilateral immigration policies and the cycle is quite low and requires more than a year to be of significant magnitude. Since this assumption is important, we further assess its validity by focusing on a set of specific cases. More precisely, we focus on the cases of four important countries: United States, Canada, Spain and France. We adopt two complementary perspectives in that respect. We first consider national acts (laws, decrees, ministries' decisions...) related to immigration that are considered in the literature as potentially reactive to business cycles. We then conduct a complementary analysis of national acts concerning visas, registered in the International Organization for Migration database, and compare the dates at which these rules were passed along with peaks and toughs of economic cycles. This comparison remains qualitative since it is very difficult to numerically code those acts (this depends among other things on the impact of their contents). This analysis is fully detailed in the Appendix B.

The analysis leads us to conclude that the contemporaneous correlation of business cycles and unilateral immigration policies is quite low. Appendix B illustrates from case studies the various reasons for this low correlation. Among those reasons, even if policies account for the economic cycle, there is clearly a time lag needed to pass the immigration laws. Also, while business cycles might be a concern, a lot of immigration acts target non economic goals. This is for instance the case for family reunification policies which affect a significant proportion of migrants. From the whole analysis, we conclude therefore that the omission of unilateral immigration policies should not invalidate the results of our empirical exercise. 


\subsubsection{Migrants Networks}

A second source of concerns is that specification (12) does not account for the effect of migrants networks. Diasporas at destination are known to generate mechanisms that lower the migration costs for the prospective migrants of their country of origin. This effect has been documented in various papers dealing with macroeconomic data (Beine et al., 2011 among others). In those models, the network is often captured by the size of the bilateral migration stock at the start of the migration period. Most of the papers consider migration periods of ten years and use either cross sectional data (Beine et al. 2011; Bertoli and Fernandez-Huertas Moraga, 2012) or panel data (Beine and Parsons, 2014). In the context of this paper, bilateral migration stocks are unavailable at an annual frequency, which explains the omission of the network in specification (12). One question is whether this is detrimental for the estimations of our models. In that respect, some comments are in order here.

First, the empirical literature emphasizes the variation of network elasticities across types of migration processes. The network effect is obviously more important for unskilled migrants and for South-North migration. While it is not negligible for North-North migration and skilled migrants, the fact that we focus on migration flows among OECD countries makes the omission of the network less serious. Second, at the annual frequency, migration stocks are quite stable over time. These are for a lot of country pairs quite collinear to some fixed effects, and in particular with the dyadic ones $\left(\alpha_{i j}\right)$. This implies that models with $\alpha_{i j}$ fixed effects partly account for some implicit network effect. Finally, our observable variable capturing the bilateral agreements is likely to be highly correlated with some of the bilateral stocks. In that sense, part of the effect associated to the migrants networks is also reflected in the elasticity of that variable. ${ }^{29}$ All in all, while the inclusion of the network variables should be desirable if data were available, the specifications of our models and the sample of countries over which estimations are conducted make the omission of those effects less concerning.

\section{Conclusion}

In this paper, we empirically test the impact of macroeconomic fluctuations on migration flows. We revisit an old issue but with a fresh approach building the recent advances in the empirical literature on international migration. By contrast with some previous macroeconomic approaches evaluating the degree of labour mobility through indirect evidence, we

\footnotetext{
${ }^{29}$ Another possibility to account for the network effect would be to use lagged migration flows as a control variable. There are nevertheless two weaknesses associated to that strategy. First, it is unclear how migration flows correlate with stocks that proxy the networks. Second, using lagged dependent variables in panel data models with fixed effects generates some bias in the estimated parameters. This is known as the Nickell bias (Nickell 1981). The magnitude of the bias depends on the relative cross-sectional dimension with respect to the time dimension. The higher the number of dyads compared to the number of time periods, the higher the expected bias. Here we have 696 dyads (651 with missing data) and 31 time periods, which suggests that the bias would be not negligible.
} 
adopt a more direct approach relating gross migration flows and macroeconomic fluctuations. In particular, we rely on micro-founded gravity models that include the traditional long-run determinants and take into account important concepts such as the multilateral resistance terms. Our analysis looks specifically at the sensitivity of gross migration flows to relative business cycles and relative employment rates. These variables act as signals in the formation of expectations about future employment probabilities among prospective agents.

In particular we find evidence that relative business cycles and employment rates affect the intensity of gross bilateral flows. Variations of these relative short-run factors driven by the changes of economic conditions at the destination turn out to be important for the optimal destination choices of the prospective international migrants. As a by-product of this analysis, we also show that the introduction of the Schengen agreement and the inception of the common currency in EU significantly raised the international mobility of workers between the relevant countries. These results are important as they show that, compared to previous studies conducted in the 90's, labour mobility in EU seems to have increased and has become more reactive to asymmetric shocks. This dimension is key in the traditional definition of an Optimum Currency Area. This of course does not mean that Europe has become an Optimum Currency Area but suggests that labour mobility as an adjustment mechanism is more a reality than in the past. A caveat of this analysis is that we consider only homogeneous labour. Due to data constraints, we are unable to evaluate the sensitivities to business cycle fluctuation of agents distinguished by skill or education level. Such an investigation would indeed be a natural direction for the future research agenda.

\section{Appendix A - Data sources and details}

\section{A.1 International immigration data}

Table (4) provides details on source of international immigration data by destination country. Greater details are provided in the Banque de France WP version of the paper. ${ }^{30}$

[Table 4 about here.]

\section{A.2 Sources of data capturing the bilateral agreements}

[Table 5 about here.]

We build a variable taking a value of 1 for a couple of countries when a bilateral labour agreement exists between these two countries, or when a general law easing foreigners' entrance has been passed. When no agreement or law exists, the variable is set to zero.

\footnotetext{
${ }^{30}$ This version is available at https://www.banque-france.fr/en/economics-statistics/research/workingpaper-series/document/453-1.html
} 
The main source is the International Organization for Migrations. The corresponding list of agreements can be consulted at the following link: http://www.imldb.iom.int/changeLocale.do This main source has been complemented with the information from the North America Free Trade Agreement, which to a certain extent, facilitated labour migrations between the United States and Canada after 1994.

On the other hand, important migrations exist between the members of the Commonwealth, but without any formal agreement, as confirmed in an OECD source:

http://www.oecd-ilibrary.org/fr/social-issues-migration-health/migration-et-emploi_9789264108707fr

In this latter case, the variable taking into account bilateral agreements does not take the value of one because these agreements are only implicit and, as this situation existed already before the beginning of the period under review in our article, there is no variability over time. Thus, these implicit agreements are absorbed by dyadic fixed effects.

\section{A.3 Sources of data capturing illegal and cross-border migrations}

Sources used to identify suspected illegal migration country-pairs are given in the table below.

[Table 6 about here.]

In order to conduct robustness analysis we use two sources to identify the observations for which cross-border workers represent a significant share. The primary source of identification relies on a scientific report from the European Commission on the mobility of cross-border workers within the EU27/EEA/EFTA countries published in 2009. We complement this information with a report on cross-border workers between the US and Canada.

\section{Appendix B - Analysis of legal acts related to immigration and visas}

In order to analyze the potential impact of business cycles on migrations acts among the countries in our sample, we focus on the cases of four important countries, namely the United States, Canada, Spain and France. With this sample, two non-European and two European countries are covered and they all have a sufficient size and/or large enough immigrations flows to be somewhat representative, though having their own characteristics. To that purpose, we use two complementary perspectives.

We first consider national acts (laws, decrees and ministerial decisions) related to immigration that are considered in the literature as reactions to business cycles. Canada seems to select relatively more immigrants, and to set more quantitative limits that may be changed quite rapidly, since these limits are likely to change merely by ministerial decisions. The United States have also set numerical limitations for employment-based legal permanent residents, 
but this number (140.000 immigrants a year, set by the Congress in 1990) has not fluctuated since then. There are more fluctuations for specific cases like temporary reasons in the United States, but fluctuations may be caused by non-economic motives (Cf. the events of 11th September 2001). As regards Spain, legal acts aiming at regulating immigration have come late and were rather directed towards countries out of our sample. France seems to be in an intermediate situation, since it indeed uses lists of workforce shortages to regulate economic immigration, but indicators of job vacancies are set with a lag of one year and bilateral agreements establishing lists of jobs in labour shortage concern mainly countries out of our sample. Moreover, many immigrants in our sample still come to France for non economic reasons (family reunification...).

We also make a complementary analysis of national acts concerning visas, registered in the International Organization for Migration database, and compare the dates at which these rules were passed with the economic cycles. This comparison remains qualitative: we have chosen not to give a value to these rules to include them in regressions because numerical values are cumbersome to code (this depends among other things on the impact of their contents). As it can be seen from the figure hereafter, we find that national laws about visas are not changed at regular intervals and that these changes do not in general correspond to any particular pattern of economic activity. This is due to a large extent to time lags between an economic downturn

and the moment when policies are decided and voted, which may involve a significant amount of time.

[Figure 2 about here.]

\section{Appendix C - Robustness check: estimations with dropped destinations}

This section provides the figures relative to the robustness checks of the estimation of model (12). The evolution of the coefficients can be used as indirect evidence in favour or against the validity of the underlying IIA assumptions in the estimated specifications.

Figure 3 plots the evolution of the estimated key coefficients of equation (12) when successively dropping one destination country from the regression with growth rates. The upper-left panel of Figure 3 plots the estimated values of the coefficient relative to wage differential, i.e. $\hat{\beta}_{1}$ of equation(12). The upper-right, lower-left and lower-right panels do the same for coefficients $\hat{\beta}_{2}, \hat{\beta}_{3}$ and $\hat{\beta}_{4}$ respectively.

[Figure 3 about here.] 


\section{References}

[1] Anderson, J. E., 2011. The Gravity Model. Annual Review of Economics, vol. 3, pp. 133-160.

http://dx.doi.org/10.1146/annurev-economics-111809-125114

[2] Anderson, J. E. and E. Van Wincoop, 2003. Gravity with Gravitas: A Solution to the Border Puzzle. American Economic Review, vol. 69 (1), pp. 106-116.

http://dx.doi.org/10.1257/000282803321455214

[3] Ball, L. M., Leigh D. and Loungani P., 2013. Okun's Law: Fit at Fifty ?, NBER Working Paper No. 18668.

http://www.nber.org/papers/w18668

[4] Baltagi, B. H., 1995. Econometric Analysis of Panel Data, Wiley, London.

[5] Beetsma, R. and Giuliodori M., 2010. The Macroeconomic Costs and Benefits of the EMU and Other Monetary Unions: An Overview of Recent Research. Journal of Economic Literature, 48, 603-641. http://dx.doi.org/10.1257/jel.48.3.603

[6] Beine, M., Docquier F. and Özden, C., 2011. Diasporas. Journal of Development Economics, 95(1), 30-41.

http://dx.doi.org/10.1016/j.jdeveco.2009.11.004

[7] Beine, M. and Parsons, C., 2014. Climatic Factors as Determinants of International Migration. Forthcoming in the Scandinavian Journal of Economics.

[8] Belot, M. and Ederveen, S., 2012. Cultural barriers in migration between OECD countries. Journal of Population Economics, Springer, vol. 25(3), pages 1077-1105, July. http://dx.doi.org/10.1007/s00148-011-0356-x

[9] Bertoli, S. and Fernandez-Huerta Moraga, J., 2012. Visas Policies, Networks and the Cliff at the Border. IZA Discussion Paper 2012, December. 
[10] Bertoli, S. and Fernandez-Huerta Moraga, J., 2013a. Multilateral Resistance to Migration. Journal of Development Economics, 102, 79-100.

http://dx.doi.org/10.1016/j.jdeveco.2012.12.001

[11] Bertoli, S., Brücker, H. and Fernandez-Huerta Moraga, J., 2013b. The European Crisis and Migration to Germany: Expectations and the Diversion of Migration Flows. CERDI Working Paper, No. 2013.2, University of Auvergne.

[12] Blanchard, O. J. and Katz, L. F., 1992. Regional Evolutions. Brookings Papers on Economic Activity, Economic Studies Program, The Brookings Institution, vol. 23(1), pages 1-76. http://dx.doi.org/10.2307/2534556

[13] Borjas, G. J., 1987. Self-selection and the earnings of immigrants. American Economic Review, 77 (4), 531-53.

[14] Borjas, G. J., Freeman, R. B. and Katz, L., 1996. Searching for the Effect of Immigration on the Labor Market. American Economic Review, American Economic Association, vol. 86(2), pages 246-51, May.

[15] Borjas, G. J., 2006. Native Internal Migration and the Labor Market Impact of Immigration. Journal of Human Resources, 41(2), 221-258. http: //dx.doi.org/10.3368/jhr.XLI.2.221

[16] Card, D., 2001. Immigrant Inflows, Native Outflows, and the Local Labor Market Impacts of Higher Immigration. Journal of Labor Economics, University of Chicago Press, vol. 19(1), pages 22-64, January. http://dx.doi.org/10.1086/209979

[17] Card, D., 2005. Is the New Immigration Really so Bad?. The Economic Journal, 115, 300-323.

http://dx.doi.org/10.1111/j.1468-0297.2005.01037.x

[18] Chiquiar, D. and Hanson, G., 2005. International Migration, Self-Selection, and the Distribution of Wages: Evidence from Mexico and the United States. Journal of Political Economy, 113(2), 239-281 http://dx.doi.org/10.1086/427464 
[19] Clark, X., Hatton, T. J. and Williamson, J. G., 2007. Explaining U.S. Immigration, 1971-1998. The Review of Economics and Statistics, MIT Press, vol. 89(2), pages 359-373, May.

http://dx.doi.org/10.1162/rest.89.2.359

[20] Coulombe, S., 2006. Internal Migration, Asymmetric Shocks, and Interprovincial Economic Adjustments in Canada. International Regional Science Review, 29(2), 199-223. http://dx.doi.org/10.1177/0160017606286357

[21] De Grauwe, P., 2009. Economics of Monetary Union, 8th edition, Oxford University Press, Oxford, UK.

[22] Docquier, F. and Marfouk, A., 2006. International migration by educational attainment (1990-2000), in C. Özden and M. Schiff (eds). International Migration, Remittances and Development, Palgrave MacMillan: New York (2006), chapter 5.

[23] Docquier, F., Marfouk, A. and Lowell, B. L., 2009. A Gendered Assessment of Highly Skilled Emigration. Population and Development Review, 35, 297-322.

http://dx.doi.org/10.1111/j.1728-4457.2009.00277.x

[24] Docquier, F., Özden, C. and Peri, G., 2013. The Labor Market Effects of Immigration and Emigration in OECD Countries. The Economic Journal, Royal Economic Society, vol. 124 (579), pages 1106-45.

http://dx.doi.org/10.1111/ecoj.12077

[25] Frankel, J. A. and Rose, A. K., 1998. The Endogeneity of the Optimum Currency Area Criteria, The Economic Journal, Royal Economic Society, vol. 108(449), pages 1009-25, July.

http://dx.doi.org/10.1111/1468-0297.00327

[26] Gibson, J. and McKenzie, D., 2011. The Microeconomic Determinants of Emigration and Return Migration of the Best and Brightest: Evidence from the Pacific. Journal of Development Economics, 95(1), 18-29.

http://dx.doi.org/10.1016/j.jdeveco.2009.11.002

[27] Gordon, R. J., 2010. Revisiting and Rethinking the Business Cycle, Okun's Law and Productivity Innovations. American Economic Review: Papers \& Proceedings 100, May 
2010: 11-15.

http://dx.doi.org/10.1257/aer.100.2.11

[28] Grogger, J. and Hanson, G. H., 2011. Income Maximization and the selection and sorting of international Migrants. Journal of Development Economics, 95(1), 42-54.

http://dx.doi.org/10.1016/j.jdeveco.2010.06.003

[29] Harris, J. R. and Todaro, M. P., 1970. Migration, Unemployment and Development: A Two-Sector Analysis, American Economic Review, American Economic Association, vol. 60(1), pages 126-42, March.

[30] Head, K., J. Ries and Swenson, D., 1995. Agglomeration Benefits and Location Choice: Evidence from Japanese manufacturing investments in the United States. Journal of International Economics, 38, 223-247.

http://dx.doi.org/10.1016/0022-1996(94)01351-R

[31] Lee J., 2000. The Robustness of Okun's law: Evidence from OECD countries. Journal of Macroeconomics, 22, 331-356.

http://dx.doi.org/10.1016/S0164-0704(00)00135-X

[32] Mayda, A. M., 2010. International migration: A panel data analysis of the determinants of bilateral flows. Journal of Population Economics, Springer, Springer, vol. 23(4), pages 1249-1274, September.

http://dx.doi.org/10.1007/s00148-009-0251-x

[33] McFadden, D., 1984. Econometric analysis of qualitative response models. In: Z. Griliches and M. Intriligator, eds., Handbook of Econometrics, Volume 2, Amsterdam. Elsevier/North-Holland.

[34] McKenzie, D., Theoharides, C. and Yang, D., 2014. Distorsions in the International Migrant Labor Market: Evidence from Filipino Migration and Wage Responses to Destination Country Economic Schocks. American Economic Journal: Applied Economics, American Economic association, 6(2), 49-75, April.

http://dx.doi.org/10.1257/app.6.2.49

[35] McKenzie, D. and Rapoport, H., 2010. Self-selection patterns in Mexico-US migration: the role of migration networks. Review of Economics and Statistics, 92(4), 811-821. 
http://dx.doi.org/10.1162/REST_a_00032

[36] Mundell, R. A., 1961. A Theory of Optimum Currency Areas. The American Economic Review, Vol. 51, No. 4 (Sep., 1961), pp. 657-665.

[37] Nickell, S. N., 1981, Biases in Dynamic Models with Fixed Effects, Econometrica, 49, pp. 1419-1426.

[38] OECD, 2007. International Migration Outlook 2007. Paris: Organisation for Economic Co-operation and Development.

[39] Ortega, F. and Peri, G., 2013. The Effect of Income and Immigration Policies on International Migration. Migration Studies, 1, 1-28. Oxford University Press. http://dx.doi.org/10.1093/migration/mns004

[40] Ottaviano, G. and Peri, G., 2012. Rethinking the Impact of Immigration on Wages. Journal of the European Economic Association, 10(1), 152-197. http://dx.doi.org/10.1111/j.1542-4774.2011.01052.x

[41] Özden, C., Parsons, C., Schiff, M. and Walmsley, T., 2011. Where on Earth is Everybody?. World Bank Economic Review, vol. 25(1), 13-58. http://dx.doi.org/10.1093/wber//hr024

[42] Pedersen, P. J., Pytlikova M. and Smith N., 2008. Selection and network effects-Migration flows into OECD countries 1990-2000. European Economic Review, 52 (7), 1160-1186. http://dx.doi.org/10.1016/j.euroecorev.2007.12.002

[43] Pissarides, C. A. and McMaster, I., 1990. Regional Migration, Wages and Unemployment: Empirical Evidence and Implications for Policy. Oxford Economic Papers New Series, Vol. 42, No. 4, 812-831.

http://www.jstor.org/stable/2663123

[44] Roy, A. D., 1951. Some thoughts on the distribution of earnings. Oxford Economic Papers, 3 (2), 135-46. 
[45] Rosenzweig, M. R., 2006. The Circulation Migration of the Skilled and Economic Development. Proceedings Federal Reserve Bank of Dallas, 147-170.

[46] Santos Silva, J. M. C. and Tenreyro, S., 2006. The Log of Gravity. Review of Economics and Statistics, 88 (4): 641-658. http://dx.doi.org/10.1162/rest.88.4.641

[47] Simpson, N. and Sparber, C., 2012. The Short- and Long-Run Determinants of LessEducated Immigrant Flows into U.S. States. Colgate University, Mimeo. 
Table 1: Business cycles and migration: benchmark regression

\begin{tabular}{l|cc|cc}
\hline \hline Estimation Method & \multicolumn{2}{|c|}{ Scaled OLS } & \multicolumn{2}{c}{ OLS } \\
\hline Variables & $(1)$ & $(2)$ & $(3)$ & $(4)$ \\
\hline Wage & $0.766^{* * *}$ & $0.903^{* * *}$ & $0.736^{* * *}$ & $0.872^{* * *}$ \\
& $(13.40)$ & $(15.04)$ & $(12.45)$ & $(13.99)$ \\
Business cycle & $0.0067^{* * *}$ & $0.019^{* * *}$ & $0.0068^{* * *}$ & $0.018^{* * *}$ \\
& $(2.91)$ & $(6.77)$ & $(2.91)$ & $(6.11)$ \\
Employment rate & $5.250^{* * *}$ & $5.614^{* * *}$ & $5.223^{* * *}$ & $5.611^{* * *}$ \\
& $(14.52)$ & $(18.32)$ & $(14.37)$ & $(10.70)$ \\
Schengen & $0.252^{* * *}$ & $0.243^{* * *}$ & $0.262^{* * *}$ & $0.252^{* * *}$ \\
& $(11.66)$ & $(11.25)$ & $(12.03)$ & $(11.63)$ \\
EMU & $0.137^{* * *}$ & $0.139^{* * *}$ & $0.139^{* * *}$ & $0.140^{* * *}$ \\
& $(4.88)$ & $(4.99)$ & $(4.94)$ & $(5.03)$ \\
Bilateral & $0.097^{* * *}$ & $0.095^{* * *}$ & $0.094^{* * *}$ & $0.094^{* * *}$ \\
& $(4.36)$ & $(4.27)$ & $(4.22)$ & $(4.20)$ \\
\hline Dyadic FE $\left(\alpha_{i j}\right)$ & Yes & Yes & Yes & Yes \\
Origin-time FE $\left(\alpha_{i t}\right)$ & Yes & Yes & Yes & Yes \\
\hline \# observations & 13483 & 13277 & 13416 & 13211 \\
$R^{2}$ & 0.952 & 0.952 & 0.951 & 0.951 \\
RMSE & 0.4723 & 0.4696 & 0.4745 & 0.4723 \\
\hline
\end{tabular}

Estimated equation: equation (12). Estimation period: 1980-2010.

Dep. variable in (1-2): $\ln \left(1+N_{i j, t}\right)$. Dep. variable in (3-4): $\ln \left(N_{i j, t}\right)$.

Business cycle measure: (1) and (3): HP filter.

Business cycle measure: (2) and (4): Annual growth rates.

Superscripts $* * *, * *, *$ denote statistical significance at 1,5 and $10 \%$ respectively.

Robust t-stats are provided in parentheses. RMSE means Root Mean Squared Error. 


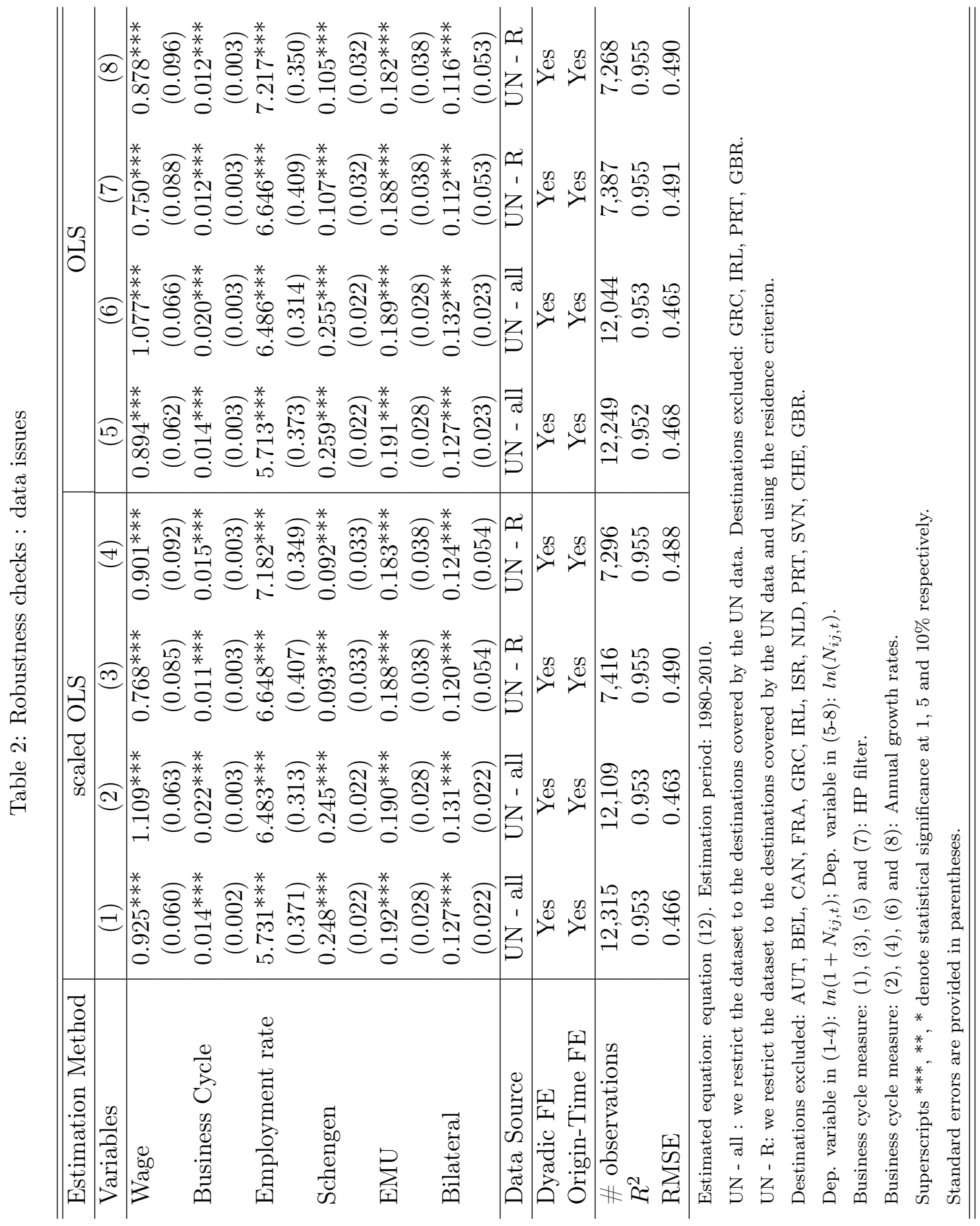




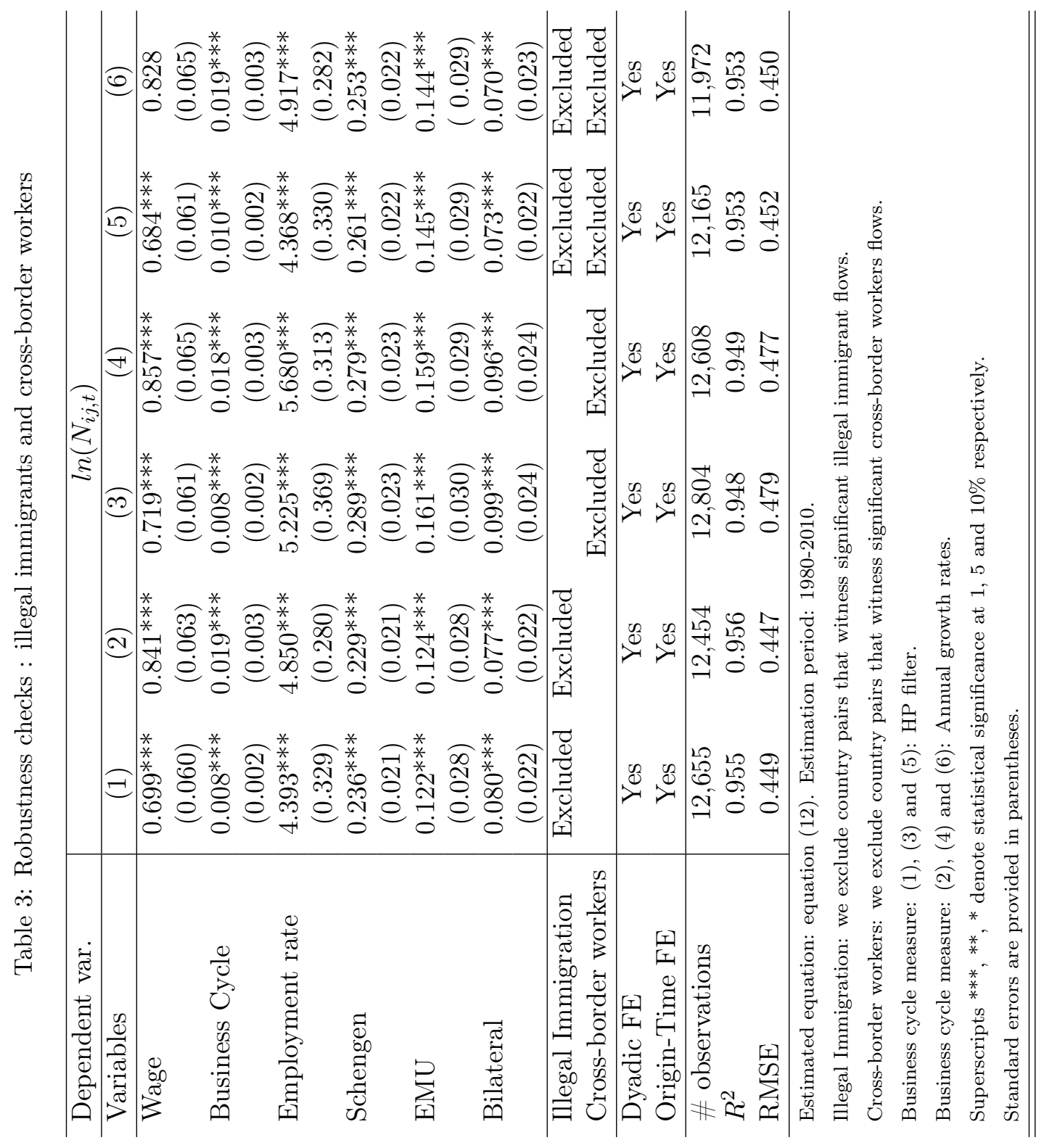


Table 4: International immigration data sources and details

\begin{tabular}{lll} 
Destination country & Data source & Migration criterion \\
\hline Australia & UN & Last country of residence \\
Austria & UN & Last country of residence \\
Belgium & UN & Country of citizenship \\
Canada & UN & Last country of residence \\
Czech Republic & UN & Last country of residence \\
Denmark & UN & Last country of residence \\
Finland & UN & Last country of residence \\
France & UN & Country of citizenship \\
Germany & UN & Last country of residence \\
Greece & OECD & Last country of residence \\
Iceland & UN & Last country of residence \\
Ireland & OECD & Last country of residence \\
Israel & UN & Country of citizenship \\
Italy & UN & Last country of residence \\
Netherlands & UN & Country of citizenship \\
New Zealand & UN & Last country of residence \\
Norway & UN & Last country of residence \\
Portugal & OECD & Last country of residence \\
Slovenia & UN & Country of citizenship \\
Spain & UN & Last country of residence \\
Sweden & UN & Last country of residence \\
Switzerland & UN & Country of citizenship \\
United Kingdom & OECD & Last country of residence \\
United States & UN & Country of birth \\
\hline \hline
\end{tabular}

Note: $U N$ refers to the data provided by the United nations population division.

More information is available on http://esa.un.org/unmigration/MigrationFlows.html

$O E C D$ refers to the data provided by the OECD International Migration database

This dataset is downloadable on http://stats.oecd.org/

Migration criterion specifies the definition of immigrants by destination country. 


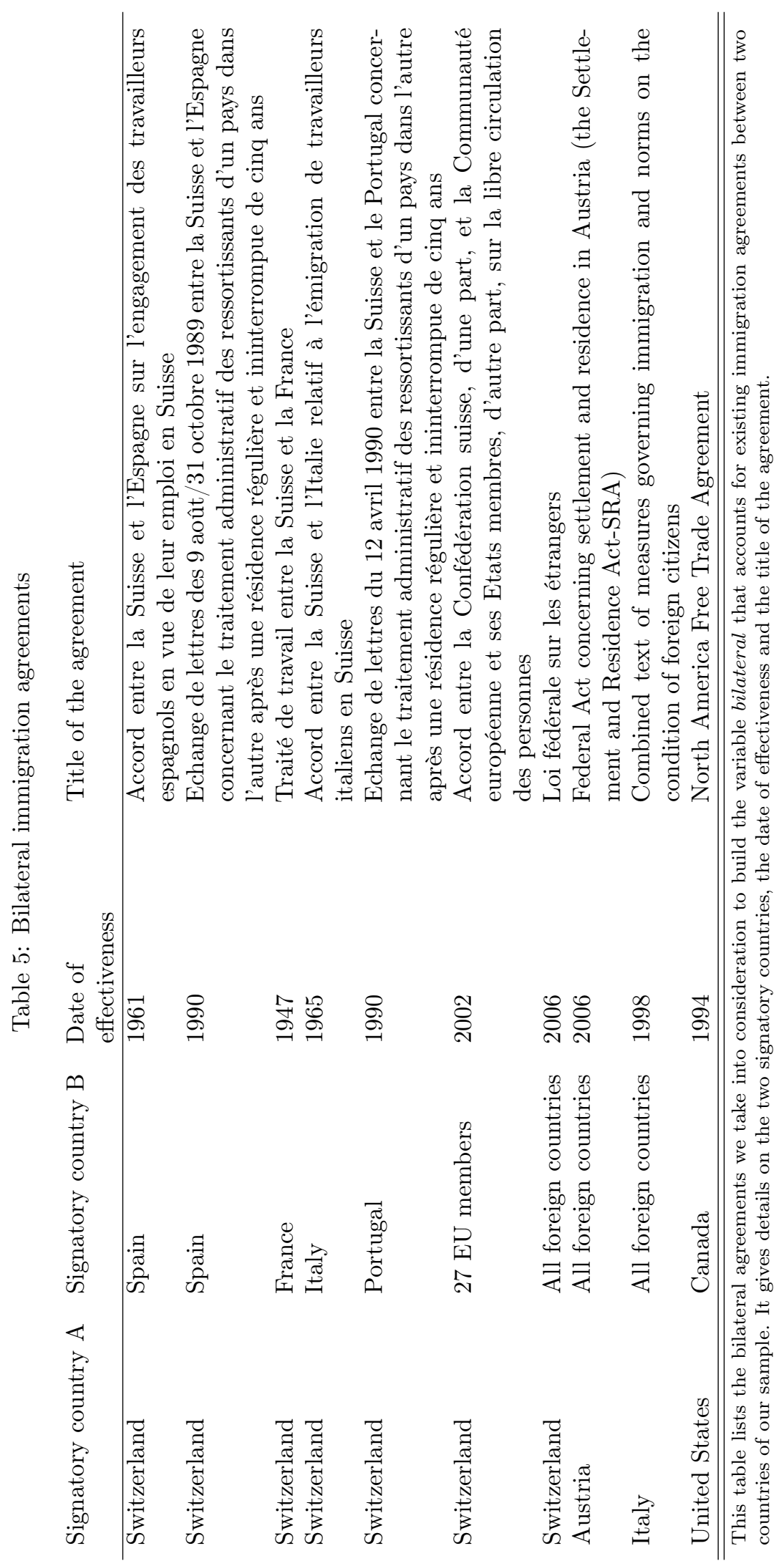


Table 6: Sources used to identify illegal migration

Destination country $\quad$ Source for illegal migration

\begin{tabular}{ll} 
Australia & Australian Government - Immigration department \\
Austria & Clandestino project report 2009 \\
Canada & Focus migration \\
Czech Republic & Clandestino project report 2009 \\
EU 15 & $\begin{array}{l}\text { Report on the first phase (1 January 2007 31 December 2008) } \\
\text { of the Transitional Arrangements set out in the 2005 Accession }\end{array}$ \\
& Treaty \\
Greece & Clandestino project report 2009 \\
Hungqry & Clandestino project report 2009 \\
Italy & Immigration Policy in Australia, Canada, New Zealand and the \\
New Zealand & United States: An overview of recent trends by Ather H. Akbari \\
& and Martha MacDonald \\
Norway & Ministry of foreign affairs \\
Spain & Clandestino project report 2009 \\
Switzerland & Office fédéral des migrations \\
The United Kingdom & Clandestino project report 2009 \\
The United States & U.S department of homeland security \\
\hline
\end{tabular}

This table gives the references used to identify significant illegal immigrant flows to the destination countries.

This allows us to perform robustness checks by dropping the country pairs for which we suspect significant illegal migrant flows. 
Figure 1: Number of missing (left axis) and zero (right axis) values for bilateral migration flows by destination country.

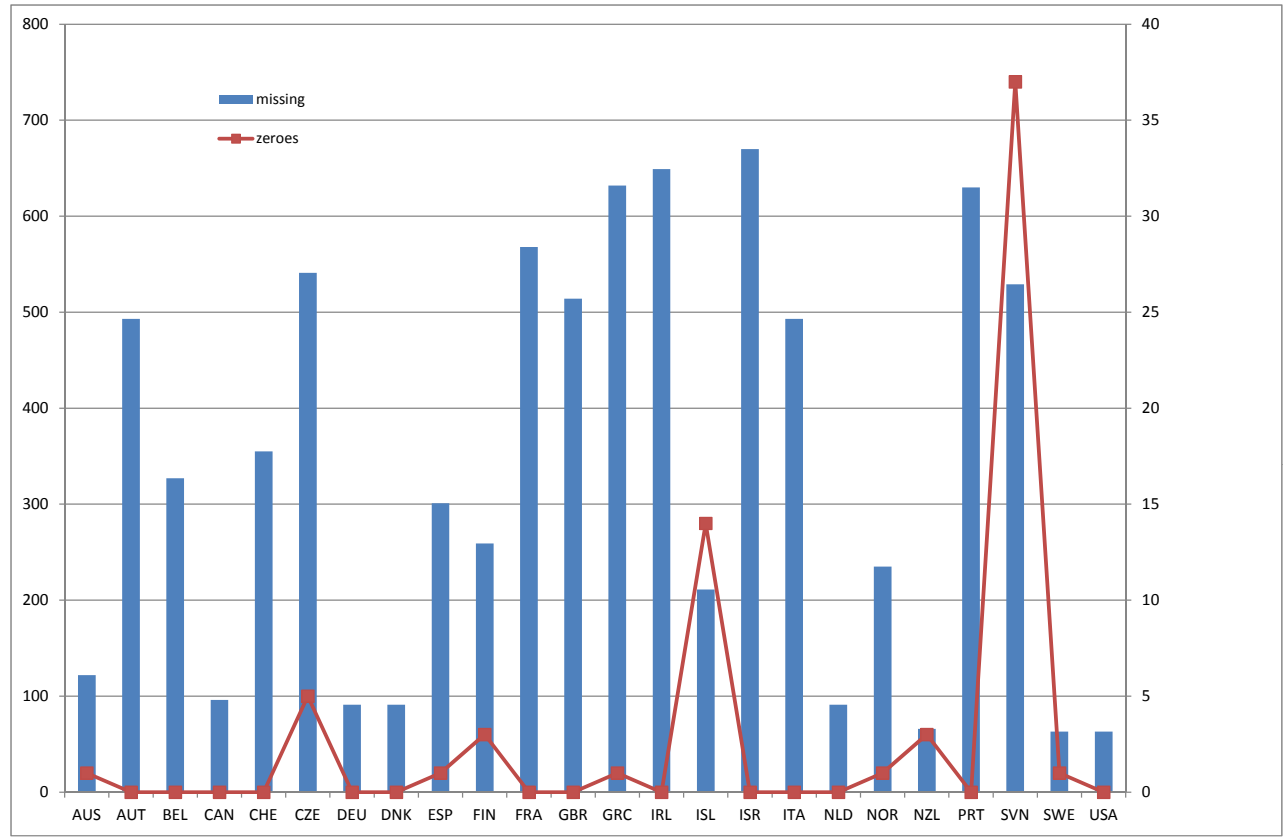

This figure plots the number of missing (left axis) and zero (right axis) values for bilateral migration flows by destination country. 
Figure 2: Business cycles and migration laws (United States, Canada, Spain and France)

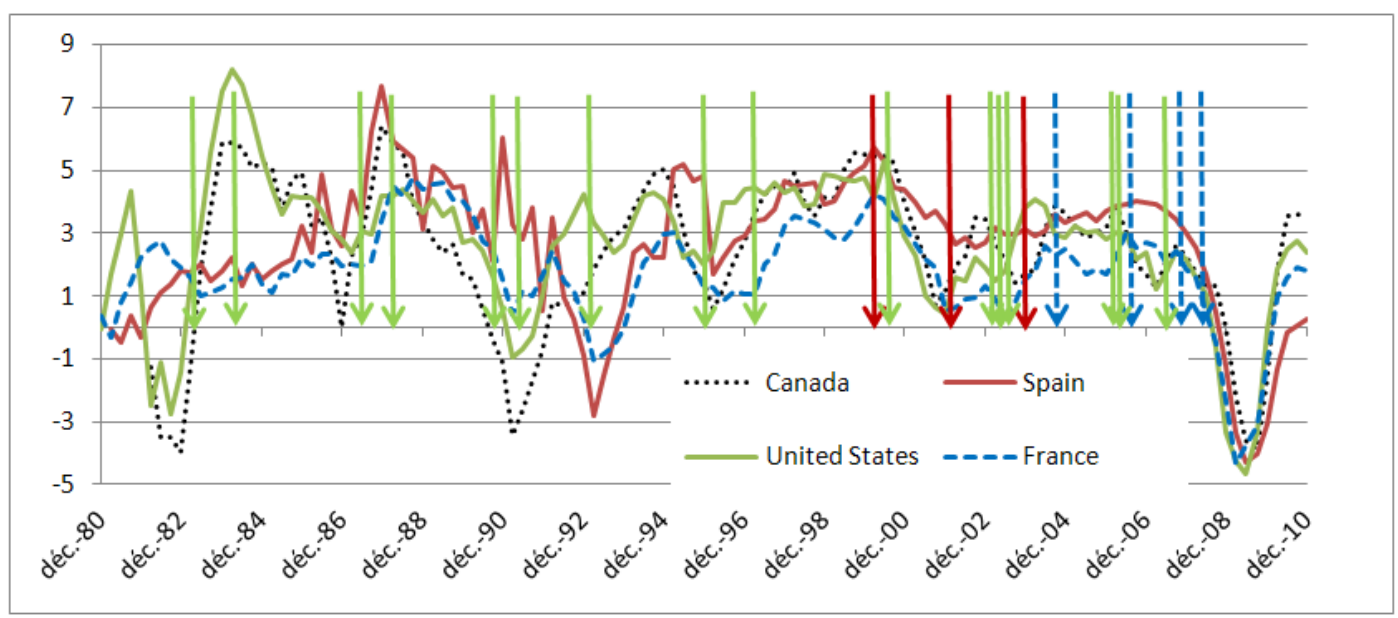

This graph plots the evolution of GDP growth rates (quarterly growth rates cumulated over four quarters, \%) and dates of acts (represented by arrows) related to visas. It focuses on four major countries of our sample. Source: IOM 


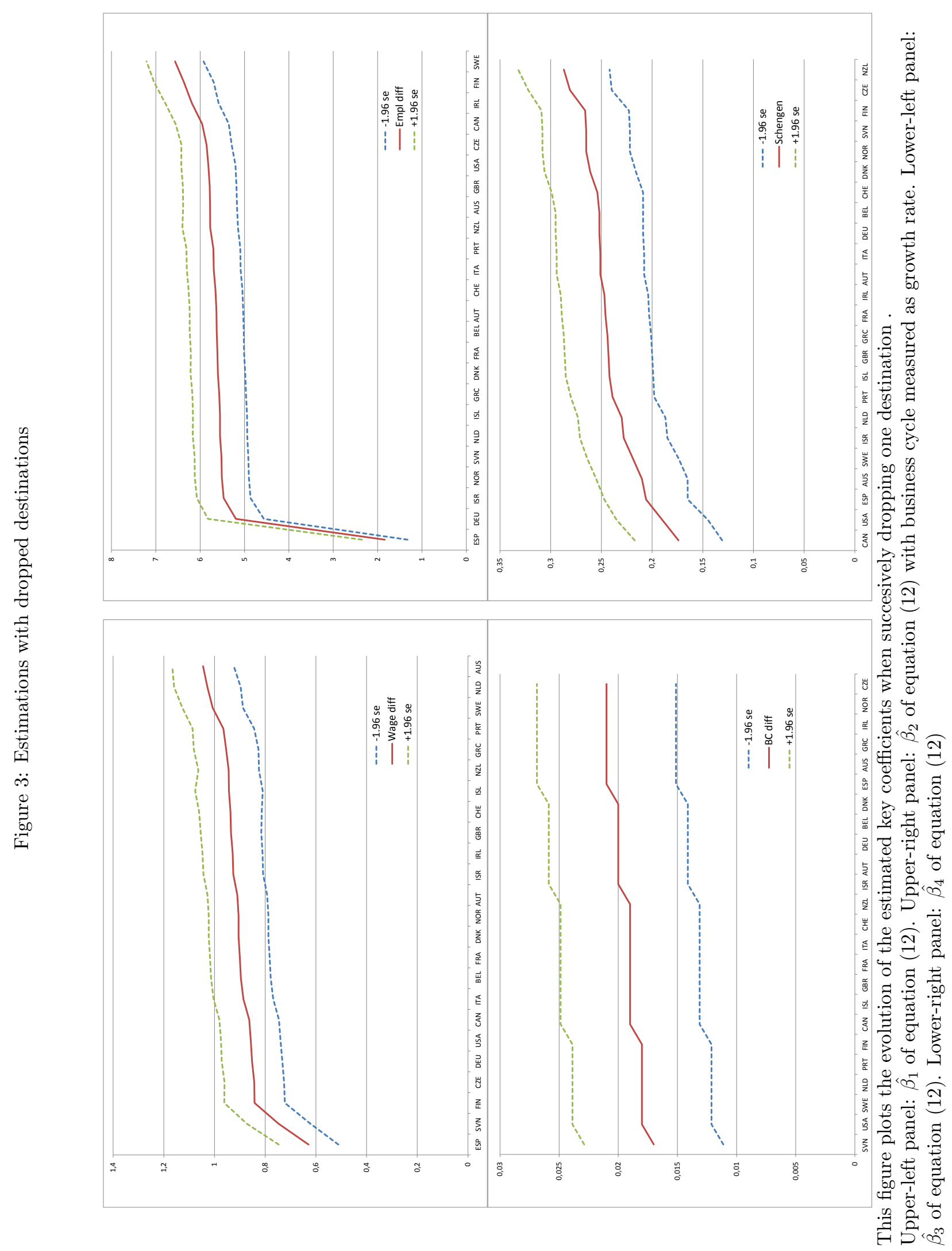

